\title{
Anatomical and clinical basis for a posterior surgical approach in fractures of the posterior parts of the lateral tibial condyle
}

\author{
A.Iu. Kochish ${ }^{1,3}$, I.G. Belen'kii' ${ }^{2}$ M.A. Kislitsin' ${ }^{1}$, B.A. Maiorov ${ }^{2,4}$ \\ ${ }^{1}$ Vreden National Medical Research Center of Traumatology and Orthopedics, Saint Petersburg, Russian Federation \\ ${ }^{2}$ Pavlov First St. Petersburg State Medical University, Saint Petersburg, Russian Federation \\ ${ }^{3}$ Kirov Military Medical Academy, Saint Petersburg, Russian Federation \\ ${ }^{4}$ Vsevolozhsk clinical inter-district hospital, Vsevolozhsk, Leningrad region, Russian Federation
}

\begin{abstract}
Introduction Conventional anterolateral surgical approach to the lateral tibial condyle has been well studied and proven safe. However, this approach does not provide adequate visualization for performing a good quality osteosynthesis in fractures located in the posterior segment of the lateral condyle. Purpose of the investigation was a rationale of plate implantation technique on the posterior surface of the lateral tibial condyle from the posterior approach with anatomical and clinical demonstration of its technical feasibility and safety. Materials and methods The study was conducted on $10 \mathrm{knee} \mathrm{joints} \mathrm{of}$ six unfixed cadavers. We implanted a T-plate on the posterior surface of the lateral tibial condyle using a posterior surgical approach. After that soft tissues were dissected to explore the exact location and the distances between the plate and crucial anatomic structures of the region. Five patients underwent surgical treatment of tibial plateau fractures $41 \mathrm{C} 3$ type following AO/OTA classification or Schatzker classification type $\mathrm{V}$ using the described method. The patients were followed-up for nine months after surgery. Results were evaluated using the KSS and Lysholm scales. Results The study on cadavers showed safety and feasibility of the surgical technique developed. We did not encounter specific complications associated with posterior plate implantation. All fractures healed after nine months post-surgery. The functional outcomes according to KSS scale were excellent in four cases and good in one case; according to Lysholm scale, three were excellent, one good and one fair outcome. Discussion In spite of the simplicity of the conventional anterolateral approach, many investigators tend to use different modifications of posterior approaches for the posterior lateral tibial condyle fixation. This method provides better reduction and fixation using a buttress plate. Our investigation showed safety and feasibility of this technique for fixation of the posterior segment of the lateral tibial condyle. The technique proposed, if performed properly, provides safe and accurate osteosynthesis and prevents secondary displacements of fragments in the rehabilitative period.
\end{abstract}

Keywords: tibial plateau fracture, fracture of tibial condyle, osteosynthesis, plate, surgical approach

\section{INTRODUCTION}

The issue of choosing a surgical approach for performing osteosynthesis of the fractures of the lateral tibial condyle has been discussed in the current scientific literature [1-3]. The most common among them is a conventional anterolateral approach (ALA) which has been well studied, sufficiently simple technically and proven by many years of practice [2, 4, 5-7]. However, this surgical approach allows visualizing the damaged parts of the distal tibial metaepiphysis (plateau) related to the lateral condyle only in its anterolateral and lateral parts. But if the location of the main bone fragments is in the posterolateral or posterior parts of the lateral tibial condyle, this approach does not provide enough visualization which is required for accurate reduction and safe fixation of the fracture. And, in particular, it does not allow osteosyntesis with a buttress plate that would prevent a posterior migration of the fragments $[1,4,8]$.
Therefore, in a line with current notions about plating that implies an accurate reduction of bone fragments, including the articular surface, there is a clear tendency to use posterior surgical approaches for osteosynthesis of posterior tibial plateau fractures that provide the shortest way to the area of main bone lesions, their good visualization and the necessary conditions for placement of posterior buttress plates [9-14]. In particular, the most commonly used among the posterior approaches to the lateral tibial condyle are the inverted L-shaped [9] and direct posterior approaches to the posterior parts of this condyle [15].

However, the posterior, listed above, have not been much used due to their relatively high technical complexity and due to the risks of injuring major anatomical structures $[4,16]$. The latter reason is of particular importance as major and significant anatomical formations are located there such as

Dochish A.Iu., Belen'kii I.G., Kislitsin M.A., Maiorov B.A. Anatomical and clinical basis for a posterior surgical approach in fractures of the posterior parts of the lateral tibial condyle. Genij Ortopedii, 2020, vol. 26, no 4, pp. 461-470. DOI 10.18019/10284427-2020-26-4-461-470 
popliteal vessels, anterior tibial artery, tibial and common peroneal nerves which possible injury restrains the surgeons from performing the posterior approach. Importantly, but special topographic and anatomical studies directed on the investigation of the convenience and safety of the approach discussed have not been conducted. The available publications that summarize the experience include a relatively small number of cases and do not allow conclusions on the advantages, drawbacks and indications to the use of this surgical approach [16, 17].

The purpose of our study was to substantiate the rationale of posterior surgical approach to the lateral tibial condyle from the topographic and anatomical positions and placement of a posterior buttress plate, to evaluate the safety of such an intervention in regard to the risks of major anatomical structure injury and the control of the rationale in clinical practice.

\section{MATERIAL AND METHODS}

Our study was approved by the institutional ethics board and was conducted in accordance with the ethical standards of the Helsinki declaration. The patients included into the study signed informed consents. This study comprises two parts, anatomical and clinical. The first part was conducted at the chair of surgery and topographic anatomy of the Kirov Military Medical Academy. Its aim was substantiation of topographic and anatomical positions of the posterior approach to the lateral tibial condyle and included an application study on 10 unfixed lower limbs of six cadavers that did not have any injuries or deformities.

The protocol of experimental interventions on the technique of the posterior approach and placement of a buttress plate along the posterior surface of the lateral tibial condyle and further preparation of the material and measurements was as follows. First, the necessary anatomical landmarks were made on the skin of the knee joint area in the position of "on healthy side" (Fig. 1). It should be noted that the main idea of studying the posterior approach is, in our opinion, in the positioning of the surgical intervention zone and placement of the plate for osteosynthesis in the gap between the major branches of the sciatic nerve, tibial and common peroneal nerves, what is well seen in the diagram (Fig. 2).

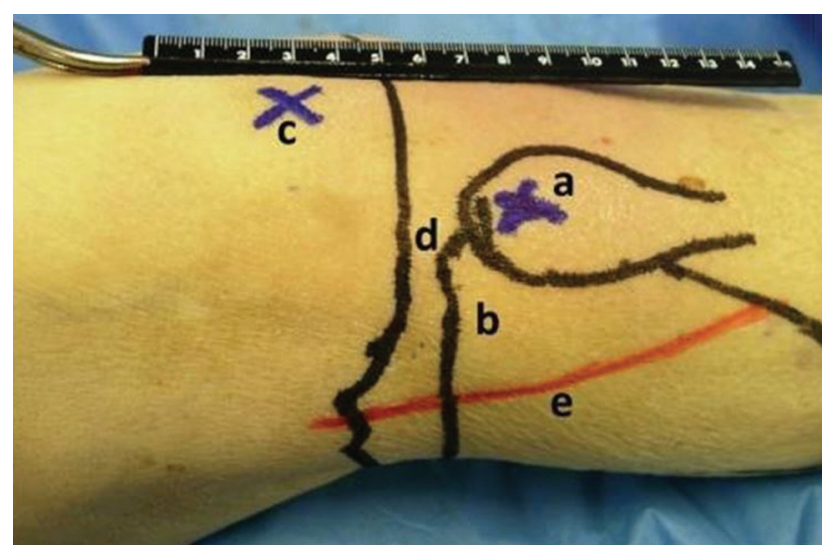

Fig. 1 Main anatomical orientations in the knee joint area for executing the posterior approach to the lateral tibial condyle: $\boldsymbol{a}$ fibular head; $\boldsymbol{b}$ lateral tibial condyle; $\boldsymbol{c}$ lateral femoral epicondyle; $\boldsymbol{d}$ line of skin incision

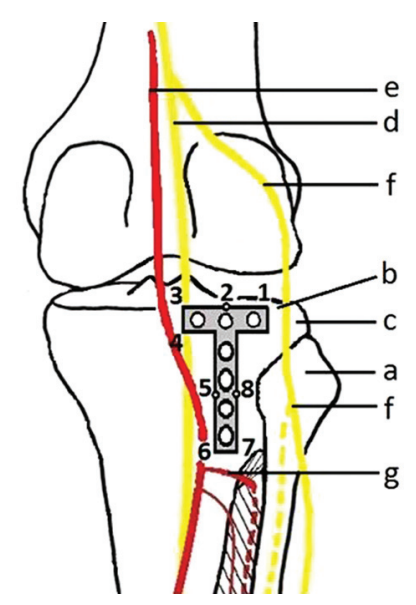

Fig. 2 Diagram of plate positioning on the posterior surface of the lateral tibial condyle through the posterior approach: $\boldsymbol{a}$ fibular head; $\boldsymbol{b}$ tibial plateau; $\boldsymbol{c}$ lateral tibial condyle; $\boldsymbol{d}$ tibial nerve; e popliteal artery; $\boldsymbol{f}$ common peroneal nerve; $\boldsymbol{g}$ anterior tibial artery

The posterior approach was initiated with a longitudinal skin incision of $9-10 \mathrm{~cm}$ from up to down along the line marked, starting from the centre of the popliteal fossa at the level of the knee joint gap and at 3 to $4 \mathrm{~cm}$ more proximal to the level of the fibular head top and runs distal and lateral at a $2-\mathrm{cm}$ distance to the medial from its medial edge. Moreover, the lower point of the incision was over the interosseous membrane by 6 to $7 \mathrm{~cm}$ more distally from the top of the fibular head. The next step, after dissection of the proper fascia and being oriented by the inner edge of the long head of the femoral biceps muscle and its tendon, the common peroneal nerve was found near the lateral edge of the surgical wound, which was partially released and brought to lateral.

The deeper part of the approach was realized between the lateral head of the gastrocnemius muscle and soleus muscle, the former was mobilized and displaced to medial and the latter to distal to the lower angle of the surgical wound. Thereby, the popliteal vascular bundle and the tibial nerve should remain medial from the zone of the tissue separation and could not be seen in the wound. These formations were displaced to the medial with a hook along with a mobilized lateral head of the gastrocnemius 
muscle, both protected from being injured. Next, the belly was found in the depth of the wound along with the attachment of the popliteal muscle tendon, which should be saved to maximum.

The next step of the experimental intervention was a vertical capsulotomy of the knee joint over the posterior surface of the lateral tibial condyle to visualize its articular and posterior surfaces. Thereby, the posterior surface of this condyle is always well seen at the extension of 3 to $5 \mathrm{~cm}$ more distal to the knee joint gap what provided the conditions for posterior buttress plate placement. Next, a T-plate was installed by moving it from above to down and orienting its transverse part parallel to the articular gap and its diaphyseal part was placed under the separated belly of the popliteal muscle. The plate was fixed proximally with three screws for spongy bone, $4.0 \mathrm{~mm}$ in diameter and $50 \mathrm{~mm}$ long, and with two cortical screws, $3.5 \mathrm{~mm}$ in diameter and $40 \mathrm{~mm}$ long, distally (Fig. 3).

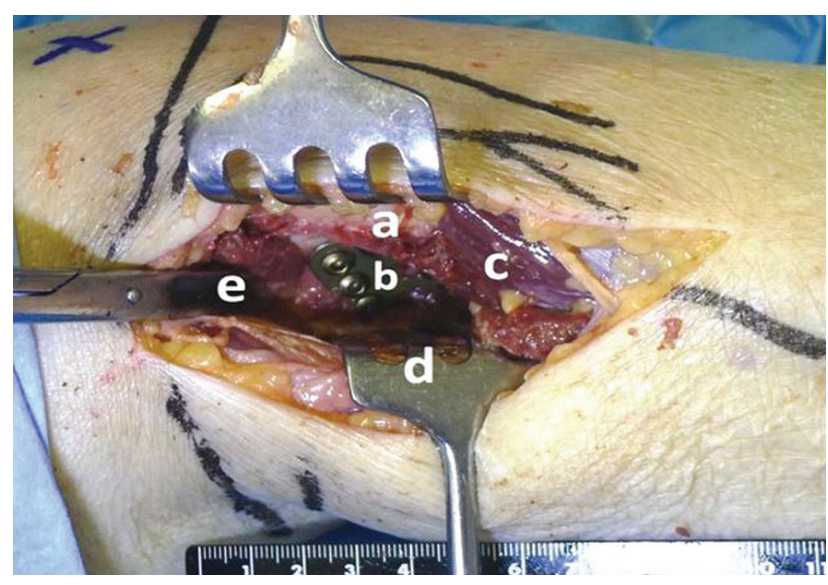

Fig. 3 Posterior approach to the lateral tibial condyle after installation of the T-plate: $\boldsymbol{a}$ fibular head; $\boldsymbol{b}$ T-plate on the posterior surface of the lateral tibial condyle; $c$ soleus muscle separated from the fibular head and shifted to the lower angle of the surgical wound; $\boldsymbol{d}$ lateral head of the gastrocnemius muscle mobilized and shifted medially with a hook along with popliteal vessels and tibial nerve; $\boldsymbol{e}$ scissors introduced into the articular knee gap from backward

The next step was a careful preparation of the region of the posterior approach to the lateral tibial condyle, revealing the position of a number of important anatomical formations relative the surgical wound and the T-plate installed: the popliteal and anterior tibial arteries as well as of the common peroneal and tibial nerves. The shortest distances were measured from eight points on the plate to the anatomical structures indicated above, as well as to specific bone marks shown on the diagram (Fig. 2). The results of the measurements were introduced into a special protocol. Photos were taken of the main stages of the experimental interventions and final outcomes of the preparations.

The technique of the surgical interventions developed and topographic and anatomical grounds were used in five operations of osteosynthesis with a T-shaped buttress plate implanted through the posterior surgical approach in five patients, three males and two females in the mean age of $59.3 \pm 12$ years, who sustained fractures classified as $\mathrm{AO} 41 \mathrm{C} 3$ and Schatzker type V. It should be noted that the fractures of the posterior part of the lateral tibial condyle were combined with fractures of the posterior sector of the medial tibial condyle in all our patients. Therefore, the operation started first with plating of the medial condyle from the conventional medial approach [2]. Then, the posterior approach was completed and the buttress plate was implanted on the posterior surface of the lateral tibial condyle according to the technique described above. All the interventions were performed at the specialized departments of the Aleksandrovskaya municipal hospital and Vsevolozhsk clinical inter-district hospital.

The outcomes of the interventions were assessed after 7-10 days, one, three, six, and nine months postoperatively. International evaluations systems were used, KSS [18] and Lysholm [19]. Radiography and computed tomography (CT) were used before the operation and at follow-ups to evaluate the displacement of the fragments of the posterior part of the lateral tibial condyle and term of fracture consolidation. Post-operative complications were revealed, and first of all, those associated with possible damage to major blood vessels and peripheral nerves.

The results of the applied topographic and anatomical study and clinical findings were compared, also with the data from the available literature.

All quantitative data obtained in the topographic/ anatomical and clinical parts of this study were statistically processed for defining the mean values and deviations ( \pm ) in Excel 2016 (Microsoft, USA).

\section{RESULTS}

The anatomical part of the study established that none of ten experimental interventions ended in the injuries of the arteries, veins or nerves indicated above. All major anatomical formations were located at a particular and safe distance from the
T-plate implanted on the posterior surface of the lateral tibial condyle what is presented in the photo of the preparation (Fig. 4). Thus, it was confirmed that damage to the major blood vessels and nerves located in the proximity to the surgical wound may 
be prevented if the conditions of the technique of the approach under discussion and plating along the posterior surface of the lateral tibial condyle are followed as was shown on the anatomical material and rational implementation of the technique.
In order to define the shortest distance from the orientation points on the T-plate to the nearest blood vessels and peripheral nerves, the following measurements were done upon completion of the preparation (Table 1).

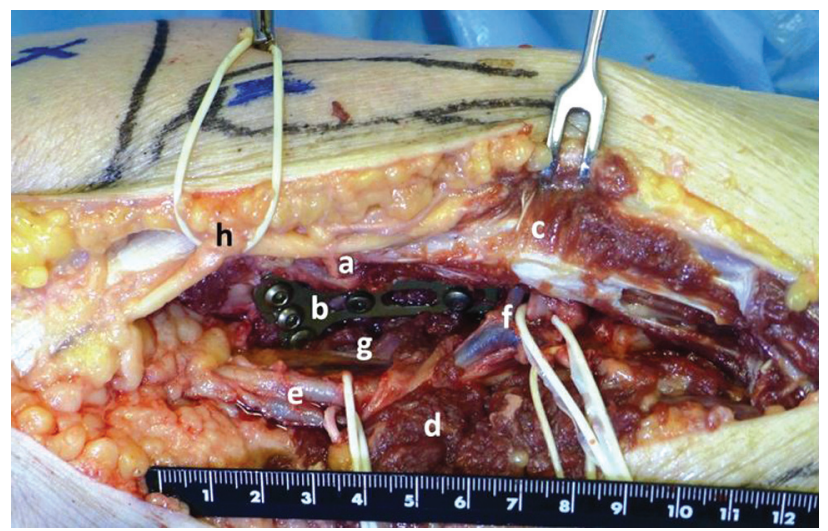

Fig. 4 Result of the preparation after the experimental operation: $\boldsymbol{a}$ fibular head; $\boldsymbol{b}$ T-plate on the posterior surface of the lateral tibial condyle; $c$ soleus muscle separated partially in the course of the preparation; $\boldsymbol{d}$ lateral head of the gastrocnemius muscle mobilized proximally and shifted medially; $\boldsymbol{e}$ popliteal artery and vein; $\boldsymbol{f}$ anterior tibial artery with veins; $\boldsymbol{g}$ popliteal muscle cut in the course of preparation; $\boldsymbol{h}$ common peroneal nerve

Table 1

Mean values of measurements made on the preparations studied after completion of the posterior approach and T-plate implantation along the posterior surface of the lateral tibial condyle

\begin{tabular}{|c|c|c|}
\hline \multicolumn{2}{|l|}{ Parameters studied and measurement units } & Mean values $( \pm)$ \\
\hline \multirow{2}{*}{ Limb segment length, $\mathrm{cm}$} & SAIA - LMT & $85.5 \pm 4.6$ \\
\hline & TFH - LMT & $37.4 \pm 1.7$ \\
\hline \multirow{2}{*}{ Lower leg circumference, $\mathrm{cm}$} & Upper third & $34.9 \pm 5.5$ \\
\hline & Middle third & $34.6 \pm 7.4$ \\
\hline \multirow{6}{*}{ Shortest distance from plate points to the popliteal artery, $\mathrm{mm}$} & 1 & $18.3 \pm 2.8$ \\
\hline & 2 & $9.9 \pm 2.1$ \\
\hline & 3 & $6.0 \pm 3$ \\
\hline & 4 & $4.9 \pm 2.9$ \\
\hline & 5 & $6.3 \pm 1.8$ \\
\hline & 6 & $6.3 \pm 0.8$ \\
\hline \multirow{7}{*}{ Shortest distance from plate points to the anterior tibial artery (ATA), mm } & 1 & $51.5 \pm 5$ \\
\hline & 2 & $50.4 \pm 5.8$ \\
\hline & 3 & $50.1 \pm 6.4$ \\
\hline & 4 & $37.2 \pm 8$ \\
\hline & 5 & $23.7 \pm 4.9$ \\
\hline & 6 & $6.1 \pm 3.4$ \\
\hline & 7 & $5.9 \pm 2.5$ \\
\hline \multirow{8}{*}{ Shortest distance from plate points to the common peroneal nerve, $\mathrm{mm}$} & 1 & $16.8 \pm 4.7$ \\
\hline & 2 & $20.8 \pm 4.3$ \\
\hline & 3 & $29.4 \pm 4$ \\
\hline & 4 & $34.3 \pm 6.5$ \\
\hline & 5 & $38.7 \pm 6$ \\
\hline & 6 & $40.1 \pm 4.7$ \\
\hline & 7 & $32.1 \pm 6.9$ \\
\hline & 8 & $32.4 \pm 4.4$ \\
\hline \multirow{8}{*}{ Shortest distance from plate points to the tibial nerve, $\mathrm{mm}$} & 1 & $28.7 \pm 3.7$ \\
\hline & 2 & $19.4 \pm 1.2$ \\
\hline & 3 & $9.7 \pm 6.5$ \\
\hline & 4 & $10.9 \pm 7.2$ \\
\hline & 5 & $12.4 \pm 4.7$ \\
\hline & 6 & $8.5 \pm 2.3$ \\
\hline & 7 & $18.5 \pm 2.3$ \\
\hline & 8 & $22.4 \pm 4.7$ \\
\hline \multicolumn{2}{|l|}{ Sortest distance from the joint gap to the anterior tibial artery, $\mathrm{mm}$} & $56.6 \pm 5.5$ \\
\hline
\end{tabular}

Notes: SAIA - superior anterior iliac axis; LMT - lateral malleolus top; FHT - top of the fibular head 
The measurements allowed for precisions of topographic and anatomical relations between the plate implanted in the experimental operation and major anatomical structures located in the proximity. In particular, in regard to the popliteal artery, it was shown that it is positioned posteriorly from the T-plate installed and the minimal distance to it is $6.0 \pm 3 \mathrm{~mm}$ from point 3 on the plate. It should be noted that this distance was always greater as the popliteal vascular band was protected and shifted medially along with the lateral head of the gastrocnemius muscle with the hook in the course of the plate placement.

In regard to the anterior tibial artery (ATA), the nearest orientation points on the plate were points 6 and 7 that were located from this blood vessel at a mean of $6.1 \pm 3.4 \mathrm{~mm}$ and $5.9 \pm 2.5 \mathrm{~mm}$. The shortest distance to the ATA from the knee joint gap was $56.6 \pm 5.5 \mathrm{~mm}$. Judging from the T-plate length of $50 \mathrm{~mm}$, it can be concluded that it could be positioned so that the distal end of the implant does not contact the ATA which after distancing from the popliteal artery runs forward through the interosseous membrane into the osseofascial envelope. Moreover, the possibility that the plate contacts this artery is practically excluded due to a close attachment of the implant to the tibial periosteum when it is fixed. Thus, both the popliteal and anterior tibial artery are located posteriorly relative the plate.

The shortest distances from the tibial nerve, which is located within the popliteal fossa posteriorly from the popliteal vessels, to the buttress plate from points 3 and 4 were $9.7 \pm 6.5 \mathrm{~mm}$ and $10.9 \pm 7.2 \mathrm{~mm}$ respectively, what exceeded the minimum distance to the popliteal artery. Therefore, the conflict between the implant and this nerve is excluded.

The common peroneal nerve was located relative to different points of the T-plate at a mean distance from $16.8 \pm 4.7 \mathrm{~mm}$ (point 1) to $40.1 \pm 4.7 \mathrm{~mm}$ (point 6). It was in the safest position in regard of possible injury among all the vessels and nerves studied. While performing the posterior surgical approach, it was identified in the surgical wound and specially protected with a hook which shifted this nerve to lateral along with the tendon of the femoral biceps. Upon placement and fixation of the plate with the screws, the common peroneal nerve was behind it at a comparatively larger distance than other vessels and nerves which were studied.

The possibility of practical use of the posterior surgical approach to the posterior parts of the lateral tibial condyle together with a traditional medial approach which was use as the first stage of the intervention for plating of the injured medial tibial condyle in the clinical part of this study. Moreover, the safety of the use of this rational technique of the posterior approach and its convenience for implementation of plating osteosynthesis were assessed. Good visualization of bone fragments and articular surface of the lateral tibial condyle was observed in all five patients. It provided good reduction of bone fragments, and fill in the residual after the reduction subchondral of the lateral tibial condyle defect with a synthetic bone substitute in three cases, and finally to fix the fracture with a posterior T-shaped buttress plate. The mean duration of the intervention which was performed after four to 14 post-injury days was $100.5 \pm 10$ minutes. It should be specially noted that there were neither lesions of the major blood vessels nor iatrogenic neuropathies, nor extensive hematomas or infectious complications in the surgical wound in the course of the interventions and in the post-operative period.

The fractures of both tibial condyles united in the terms from three to six months post-surgery. There was no radiographic loss of articular surfaces intraoperative reduction of both condyles. No changes in the angles of articular surface inclination in the frontal and sagittal planes were observed as compared with the first post-operative radiographs and CT scans in any of the cases.

Results of functional assessment of treatment outcomes according to KSS и Lysholm systems which were used within the term of nine months after the interventions are presented in Table 2. First, the outcomes were evaluated as poor according to both scales in the patients but to the 6-months follow-up after fracture consolidation, the results improved to good and excellent. At a 9-month follow-up after the operation of osteosynthesis, there were four excellent and one good result according to KSS scale; and three excellent, one good and one fair according to the Lysholm system, which confirm the efficacy of the surgical treatment.

The specific features and the outcomes in the patients with the fractures under discussion are well illustrated with a clinical case.

A 59-year old female patient was admitted to the trauma department with a closed intra-articular fracture of the posterior parts of both tibial condyles and displaced fragments. It was due to a fall at home from $1.5 \mathrm{~m}$ height (Fig. $5 \mathrm{a}$ ). The diagnosis was confirmed with CT study and was verified as AO type $41 \mathrm{C} 3$ or Schatzker type V (Fig. 5 b-d). It was decided to perform plating of the medial condyle from the traditional medial approach first followed by osteosynthsis of the lateral condyle with a posterior buttress plate from the posterior surgical approach. 
Genij Ortopedii, Vol. 26, no 4, 2020

Table 2

Functional results according to KSS и Lysholm scales in five patients included into the clinical part of the study

\begin{tabular}{|c|c|c|c|c|c|}
\hline \multirow{2}{*}{ Treatment result } & \multicolumn{5}{|c|}{ Follow-up term } \\
\hline & $7-10$ days & One months & 3 months & 6 months & 9 months \\
\hline \multicolumn{6}{|c|}{ KSS scale results } \\
\hline Poor & 5 & 5 & 3 & - & - \\
\hline Fair & - & - & 2 & - & - \\
\hline Good & - & - & - & 5 & 1 \\
\hline Excellent & - & - & - & - & 4 \\
\hline Range in points & $20-40$ & $39-51$ & $47-68$ & $72-82$ & 79-98 \\
\hline Mean value $( \pm)$ & $34.2 \pm 8.1$ & $44.6 \pm 4.5$ & $56.4 \pm 9.4$ & $76.8 \pm 4.1$ & $91 \pm 7.9$ \\
\hline \multicolumn{6}{|c|}{ Lysholm scale results } \\
\hline Poor & 5 & 5 & 3 & $\begin{array}{llll}- & & & \\
-\end{array}$ & 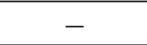 \\
\hline Fair & 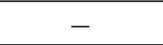 & 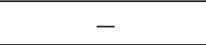 & 2 & 1 & 1 \\
\hline Good & - & 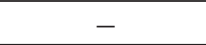 & 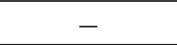 & 4 & 1 \\
\hline Excellent & - & - & - & - & 3 \\
\hline Range in points & $26-40$ & $41-55$ & $45-70$ & $66-90$ & $83-95$ \\
\hline Mean value $( \pm)$ & $33.6 \pm 5.5$ & $44.8 \pm 6.4$ & $56.6 \pm 11.5$ & $82 \pm 9.2$ & $90 \pm 5.3$ \\
\hline
\end{tabular}
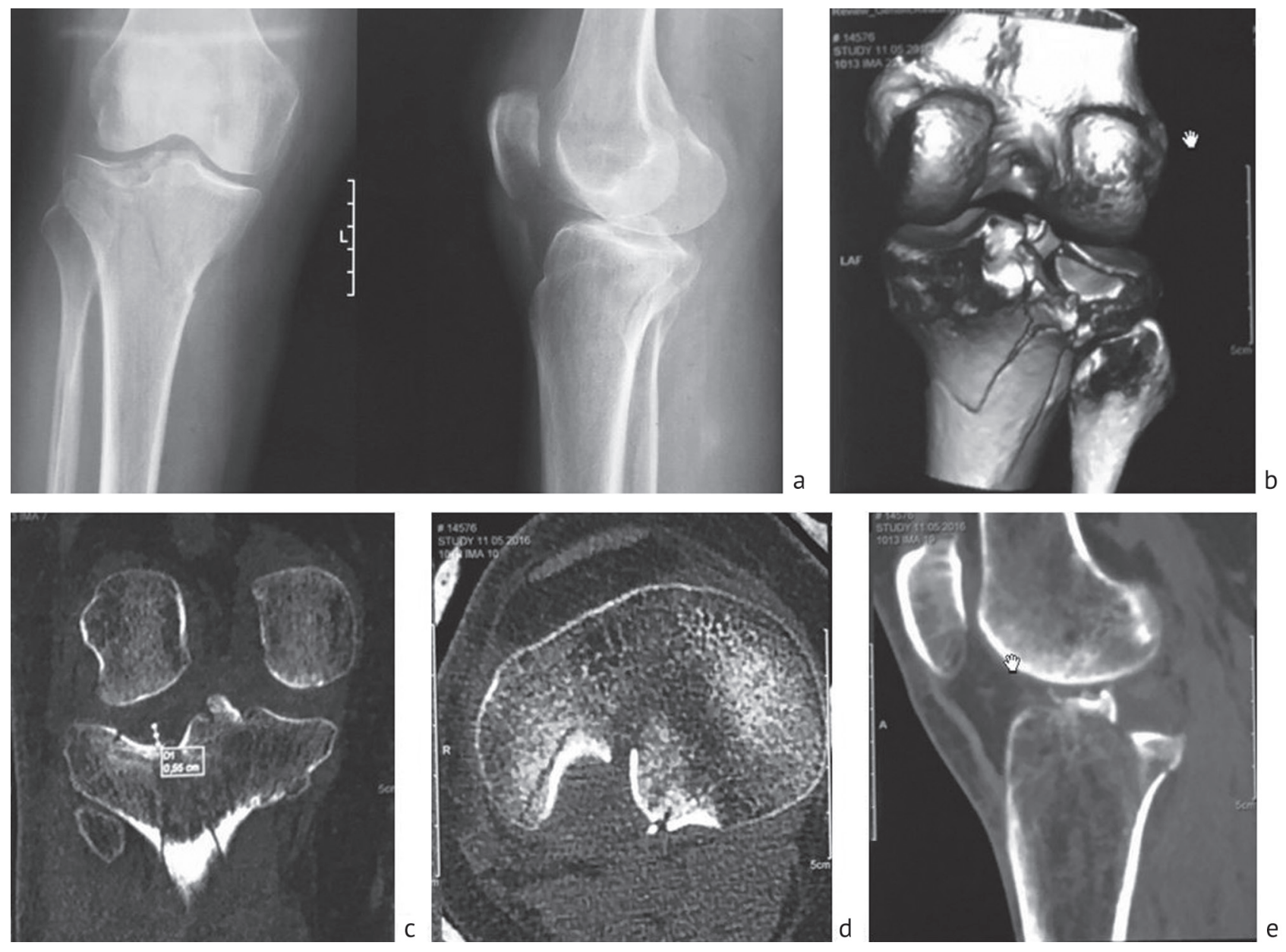

Fig. 5 Baseline radiographs and CT scans of the right knee joint in a 59-year old patient K.: $\boldsymbol{a}$ coronal and lateral radiographic views; $\boldsymbol{b} 3$-D CT-scan with a targeted бview of the lateral tibial condyle; $\boldsymbol{c}$ coronal CT scan; $\boldsymbol{d}$ axial CT scan; $\boldsymbol{e}$ sagittal CT scan

The first stage was medial approach to the medial tibial condyle in the patient positioned supine through a $10-\mathrm{cm}$ incision of skin and soft tissues to visualize the tendons of the "goose pat". Then the fracture line of the medial condyle was identified without the exposure of the knee joint cavity. Fragments of the medial tibial condyles were reduced then with a special target to achieve reduction of the metaphyseal components of the fracture. Reduction of the articular surface was done under image-intensifier control.

Once an accurate anatomical reduction of the medial tibial condyle had been achieved, it was preliminary fixed with two 1.5-mm Kirschner wires. Final fixation of this fracture with a T-plate attached with two 
$4.5 \mathrm{~mm}$ cortical screws and two $6.5-\mathrm{mm}$ cancellous screws from a set for fixation of big bone fragments followed. The plate was implanted under the tendons of the "goose foot". The first stage was completed with stitching the wound by layers and its active draining.

At the second stage the patient lie prone for producing the posterior approach to the posterior parts of the lateral tibial condyle and following the rational surgical technique developed in the course of experimental interventions on the anatomical material and described in detail above. Visualization of the injured posterior part of this condyle was sufficient for accurate open reduction of fragments involving the articular surface, and provided filling the subchondral defect formed with the synthetic substitute in the amount of $6 \mathrm{~cm}^{3}$ the placement of the T-shaped posterior buttress plate from the set for small fragment fixation and $50 \mathrm{~mm}$ long was produced from the above down, implanting its diaphyseal part under the popliteal muscle. Next, the plate was fixed proximally with three 4-mm screws for spongy bone and $50 \mathrm{~mm}$ long and distally with two $3.5 \mathrm{~mm}$ screws for cortical bone. Thereby, the ATA was not seen in the wound as it was located more distal from the lower end of the plate. The second stage was completed with stitching the wound by layers and its active draining.

Immediate post-operative period ran without complications. Active draining was removed after one day. Passive small-range movements were allowed from the second post-operative day and active from the fifth in order to restore the joint function. The checking radiographs and $\mathrm{CT}$ scans in the immediate post-operative period revealed the restoration of the knee joint anatomy with a satisfactory position of bone fragments and the implants (Fig. 6 a-c). Skin stitching was taken off on the 10th post-operative day, the wound healed by primary intention.

The follow-ups after 7 days, one, three, six and nine months after the surgery did not reveal complications associated with possible damage to major vessels or nerves in the region of the posterior approach. As far as plaster fixation was not used, the recovery of flexion in the knee joint was observed by the end of week six after passive and active exercise therapy.
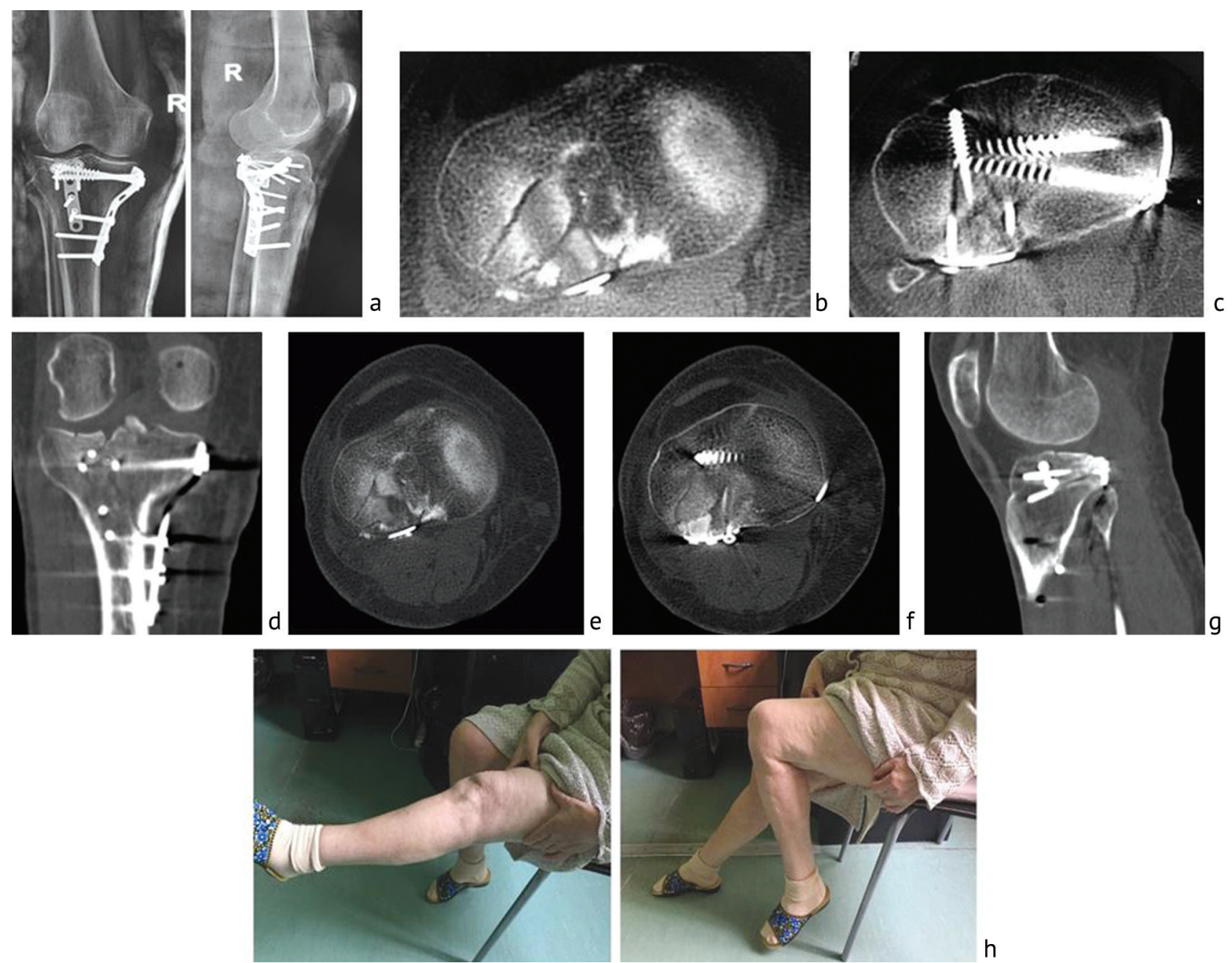

Fig. 6 Fracture union dynamics and outcome of surgical treatment in patient K., 59 years old: $\boldsymbol{a}$ radiographs of the left knee joint seven days post-surgery; $\boldsymbol{b}, \boldsymbol{c}$ axial CT scans at seven days post-surgery; $\boldsymbol{d}$ coronal CT scan at nine months post-surgery; $\boldsymbol{e}, \boldsymbol{f}$ axial CT scans at nine months post-surgery; $\boldsymbol{g}$ sagittal CT scan at nine months post-surgery; $\boldsymbol{h}$ appearance and functions of the left lower limb at 9-month follow-up 
The patient K. oa 59 years old could ambulate with crutches not loading the involved limb from the first postoperative days. By the end of the third month, muscle hypotrophy in the lower third of the femur resulted in a $1.5-\mathrm{cm}$ reduction of the segment circumference. In this time-point, she was allowed to partially load the involved limb. Excellent functional results were achieved after nine months after the osteosynthesis operation, with 87 points on the KSS scale and good Lysholm score of 86 points. The patient noted the deficit of flexion in the knee joint which was $16^{0}$ as compared with the opposite limb. CT scans did not detect either implant migration or fragment displacement of the articular surface of the tibial condyles (Fig. $6 \mathrm{e}-\mathrm{h}$ ).

\section{DISCUSSION}

The analysis of the scientific publications on the topic of osteosynthesis for fractures of the posterior parts of the lateral tibial condyle showed that the solution has not been found yet and there is no unified view in the traumatology society on this issue. Several specialists believe that the conventional anterolateral approach provides adequate reduction and fixation of these fractures [1, 5, 7, 8, 20, 21]. However, numerous opponents of this approach state that the fixation of bone fragments located in the posterior part of the lateral tibial condyle should be supported by a buttress plate and achive interfragmental compression in the fracture site what is technically impossible to perform from the anterolateral approach [9-14, 2228]. The consequence of improper fixation of such fractures would be reduction loss and disorders in the congruency of the injured joint that result in its instability in the middle term and to rapid progression of posttraumatic deforming gonarthrosis in the long term $[1,4,5,21]$.

Some specialists propose to use two separate approaches for osteosynthesis of multifragmental fractures of the lateral tibial condyle, the conventional anterolateral and additional posterior ones, that would significantly increase the invasiveness of the intervention [3]. Moreover, several proposals have been published on the use of various posterolateral surgical approaches to the posterolateral parts of the lateral tibial condyle both without fibular head osteotomy 9-14] and with its osteotomy [22-25]. An independent posterior approach to the posterior parts of the lateral tibial condyle, despite being described in several modifications [3,11, 12, 14, 15], has not gained wide application yet due to its complexity and insufficient substantiation from the topographoanatomical and clinical positions $[15,16]$ that were the ground for the research undertaken by us.

The experimental operation on an unfixed anatomical material allowed us to conclude that the posterior surgical approach is sufficiently safe if the rational surgical technique is followed in regard to the risk of injuries to the major anatomical structures located in the proximity. Moreover, it was shown that the T-plate implanted from this approach along the posterior surface of the lateral tibial condyle does not contact with large blood vessels and peripheral nerves and cannot damage them. In the course of its implantation, it is possible to shift aside all these formations and protect with plated hooks. Upon completion of the implantation, the plate is always positioned deeper than the tibial and common peroneal nerves, popliteal artery with associated veins.

In our opinion, the relationship of the posterior buttress plate with the anterior tibial artery (ATA) and associated veins is of special consideration. It was established on the anatomical material in the course of experimental operations, preparations and measurements that the distal T-plate point 6 and 7 are the closest to the ATA, as seen in the Figure 2. However, the mean minimal distances to these points were safe enough and were $6.1 \pm 3.4 \mathrm{~mm}$ and $5.9 \pm$ $2.5 \mathrm{~mm}$ respectively if the plate is not over $50 \mathrm{~mm}$ long, as used by us. Moreover, the contact of the distal end of the plate with the ATA is practically excluded because the initiation of the artery and its source, the popliteal artery, were always located behind the plate and were separated from it by the fibres of the popliteal muscle. The most anterior part of this artery ran in the tibia through the interosseous membrane more laterally to the T-plate implanted and located on the posterior surface of the tibia in its proximal part. It seems that the ATA and its accompaning veins theoretically could be injured by screw insertion to fix the distal plate part to the tibia. However, this complication can be prevented by using special tubes for protection while using the surgical drilling and burrs while preparing the canals for fixation screws.

The anatomical substantiation was checked clinically in practice. In particular, the clinical operations confirmed the safety of the posterior approach in regard to major vessels and peripheral nerves and practical measures for prevention of such lesions. An efficiency of protection of major vascular and nerve formations with flat and wide hooks to shift them to both sides from the main line of the surgical approach, lateral and medial, as well as an obligatory 
use of protection tubes for bone canal drilling should be specially noted. These protective measures had a positive effect what was confirmed as there was no considerable bleeding during osteosyntheis, severe hematomas, their infection and neuropathies of the tibial and common peroneal nerves in the postoperative period.

Thus, our comparatively little clinical experience in realizing the posterior surgical approach to the posterior parts of the lateral tibial condyle has confirmed the topographic and anatomical experimental substantiation and turned it into practical clinical use. It has been established that the posterior approach creates conditions for the quality of bone fragments reduction in the fractures under the study as well as provides reliable fixation with a posterior T-plate which is able to prevent displacements of the fragments during the consolidation process.

\section{CONCLUSION}

In general, we conclude based on the results of our applied topographic and anatomical study and small clinical experience that the posterior surgical approach for installation of a T-shaped buttress plate on the posterior surface of the lateral tibial condyle is safe enough and convenient if the technical principles developed by us are observed. In our opinion, it may be recommended for intraarticular fractures of $\mathrm{AO}$ type $\mathrm{C}$ that involve mainly the posterior parts of the lateral tibial condyle.

Moreover, we believe that this operation from the posterior approach may be indicated for combined fractures of both tibial condyles. Thereby, the fractures of the medial condyle associated with the fractures of the lateral condyle under discussion should be reduced and fixed first by plating from a separate conventional medial approach technique [2].

Indications to clinical application of the posterior surgical approach to the lateral tibial condyle, certainly, could be further revised and specified. However, the anatomical and clinical grounds for using the approach under this study, in our view, remove a number of concerns related to the risks of damage to major anatomical structures and allow its wider use in specific patients for accumulation of clinical experience.

\section{REFERENCES}

1. Malyshev E.E., Voronkevich I.A., Vtiurin A.I. Vybor dostupa pri khirurgicheskom lechenii vnutrisustavnykh perelomov proksimalnogo otdela bolshebertsovoi kosti [Choice of approach for surgical treatment of intraarticular fractures of the proximal tibia]. Sovremennye Problemy Nauki $i$ Obrazovaniia, 2019, no. 2, pp. 127. (in Russian) Available at: https://www.elibrary.ru/item.asp?id=37395161

2. Müller M.E., Allgöwer M., Schneider R., Willenegger H. Rukovodstvo po vnutrennemu osteosintezu [Manual of Internal Fixation]. M., Ad Marginem, 1996. 750 p. (in Russian)

3. Chang S.M., Hu S.J., Zhang Y.Q., Yao M.W., Ma Z., Wang X., Dargel J., Eysel P. A surgical protocol for bicondylar four-quadrant tibial plateau fractures. Int. Orthop., 2014, vol. 38, no. 12, pp. 2559-2564. DOI: 10.1007/s00264-014-2487-7

4. Kislitsyn M.A., Belenkii I.G., Maiorov B.A., Kochish A.Iu. Rezultaty osteosinteza perelomov zadnego otdela lateralnogo myshchelka bolshebertsovoi kosti s ispolzovaniem perednelateralnogo khirurgicheskogo dostupa [Results of osteosynthesis of the posterior part of the lateral tibial condyle using the anterolateral surgical approach]. Kafedra Travmatologii i Ortopedii, 2019, no. 2, pp. 48-56. (in Russian) DOI: 10.17238/ issn2226-2016.2019.2.48-56

5. Shapovalov V.M., Khominets V.V., Rikun O.V., Gladkov R.V. Khirurgicheskoe lechenie perelomov myshchelkov bolshebertsovoi kosti [Surgical treatment of fractures of the tibial condyles]. Travmatologiia i Ortopediia Rossii, 2011, no. 1, pp. 53-60. (in Russian)

6. Hsieh C.H. Treatment of the Posterolateral Tibial Plateau Fractures using the Anterior Surgical Approach. Int. J. Biomed. Sci., 2010, vol. 6, no. 4, pp. 316-320.

7. Hu S.J., Chang S.M., Zhang Y.Q., Ma Z., Du S.C., Zhang K. The anterolateral supra-fibular-head approach for plating posterolateral tibial plateau fractures: A novel surgical technique. Injury, 2016, vol. 47, no. 2, pp. 502-507. DOI: 10.1016/j.injury.2015.11.010

8. Chen H.W., Zhou S.H., Liu G.D., Zhao X., Pan J., Ou S., Fei J. An extended anterolateral approach for posterolateral tibial plateau fractures. Knee Surg. Sports Traumatol. Arthrosc., 2015, vol. 23, no. 12, pp. 3750-3755. DOI: 10.1007/s00167-014-3304-y

9. Chen H.W., Chen C.Q., Yi X.H. Posterior tibial plateau fracture: a new treatment-oriented classification and surgical management. Int. J. Clin. Exp. Med., 2015, vol. 8, no. 1, pp. 472-479.

10. Chen H.W., Liu G.D., Ou S., Zhao G.S., Pan J., Wu L.J. Open reduction and internal fixation of posterolateral tibial plateau fractures through fibula osteotomy-free posterolateral approach. J. Orthop. Trauma, 2014, vol. 28, no. 9, pp. 513-517. DOI: 10.1097/BOT.0000000000000047

11. He X., Ye P., Hu Y., Huang L., Zhang F., Liu G., Ruan Y., Luo C. A posterior inverted L-shaped approach for the treatment of posterior bicondylar tibial plateau fractures. Arch. Orthop. Trauma Surg., 2013, vol. 133, no. 1, pp. 23-28. DOI: 10.1007/s00402-012-1632-2

12. Heidari N., Lidder S., Grechenig W., Tesch N.P., Weinberg A.M. The risk of injury to the anterior tibial artery in the posterolateral approach to the tibia plateau: a cadaver study. J. Orthop. Trauma, 2013, vol. 27, no 4, pp. 221-225. DOI: 10.1097/BOT.0b013e318271f8f0

13. Sun H., Luo C.F., Yang G., Shi H.P., Zeng B.F. Anatomical evaluation of the modified posterolateral approach for posterolateral tibial plateau fracture. Eur. J. Orthop. Surg. Traumatol., 2013, vol. 23, no. 7, pp. 809-818. DOI: 10.1007/s00590-012-1067-z

14. Tao J., Hang D.H., Wang Q.C., Gao W., Zhu L.B., Wu X.F., Gao K.D. The posterolateral shearing tibial plateau fracture: treatment and results via a modified posterolateral approach. Knee, 2008, vol. 15, no. 6, pp. 473-479. DOI: 10.1016/j.knee.2008.07.004

15. Belenkii I.G., Kochish A.Iu., Kislitsyn M.A. Perelomy myshchelkov bolshebertsovoi kosti: sovremennye podkhody k lecheniiu i khirurgicheskie dostupy (obzor literatury) [Fractures of the tibial condyles: current treatment methods and surgical approaches (literature review)]. Genij Ortopedii, 2016, no. 4, pp. 114-122. (in Russian)

16. Bhattacharyya T., McCarty L.P. 3rd, Harris M.B., Morrison S.M., Wixted J.J., Vrahas M.S., Smith R.M. The posterior shearing tibial plateau fracture: treatment and results via a posterior approach. J. Orthop. Trauma, 2005, vol. 19, no. 5, pp. 305-310

17. Kochish A.Iu., Kislitsyn M.A., Belenkii I.G., Maiorov B.A., Starchik D.A. Anatomo-klinicheskoe obosnovanie zadnelateralnogo transmalobertsovogo dostupa dlia osteosinteza perelomov zadnelateralnoi kolonny plato bolshebertsovoi kosti [Anatomical-and-clinical substantiation of the posterolateral transfibular approach for osteosynthesis of fractures of the tibial plateau posterolateral column]. Travmatologiia i Ortopediia Rossii, 2019, vol. 25, no. 3, pp. 112-123. (in Russian) 
18. Kettelkamp D.B., Thompson C. Development of a knee scoring scale. Clin. Orthop. Relat. Res., 1975, no. 107, pp. 93-99. DOI: 10.1097/00003086197503000-00011

19. Tegner Y., Lysholm J. Rating systems in the evaluation of knee ligament injuries. Clin. Orthop. Relat. Res., 1985, no. 198, pp. 43-49.

20. Sun H., Zhai Q.L., Xu Y.F., Wang Y.K., Luo C.F., Zhang C.Q. Combined approaches for fixation of Schatzker type II tibial plateau fractures involving the posterolateral column: a prospective observational cohort study. Arch. Orthop. Trauma Surg., 2015, vol. 135, no. 2, pp. 209-221. DOI: $10.1007 /$ s00402-014-2131-4

21. Voronkevich I.A. Osteosintez perelomov myshchelkov bolshebertsovoi kosti v ekstrennom poriadke s ispolzovaniem plastin otechestvennogo proizvodstva [Emergency osteosynthesis of tibial condyle fractures using domestically produced plates]. Travmatologiia i Ortopediia Rossii, 2011, no. 1, pp. 87-91. (in Russian)

22. Lobenhoffer P. Posterolateral transfibular approach to tibial plateau fractures. J. Orthop. Trauma, 2011, vol. 25, no. 3, pp. e31. DOI: 10.1097/ BOT.0b013e31820b809a

23. Pires R.E.S., Giordano V., Wajnsztejn A., Oliveira Santana E. Junior, Pesantez R., Lee M.A., De Andrade M.A.P. Complications and outcomes of the transfibular approach for posterolateral fractures of the tibial plateau. Injury, 2016, vol. 47, no. 10, pp. 2320-2325. DOI: 10.1016/j.injury.2016.07.010

24. Solomon L.B., Stevenson A.W., Baird R.P., Pohl A.P. Posterolateral transfibular approach to tibial plateau fractures: technique, results, and rationale. J. Orthop. Trauma, 2010, vol. 24, no. 8, pp. 505-514. DOI: 10.1097/BOT.0b013e3181ccba4b

25. Yu B., Han K., Zhan C., Zhang C., Ma H., Su J. Fibular head osteotomy: a new approach for the treatment of lateral or posterolateral tibial plateau fractures. Knee, 2010, vol. 17, no. 5, pp. 313-318. DOI: 10.1016/j.knee.2010.01.002

26. Chu X., Liu X., Chen W., Gao J., Luo Y., Zhu J., Cai F., Zhou M. [Clinical study on treatment of posterolateral fracture of tibial plateau via superior fibular head approach]. Zhongguo Xiu Fu Chong Jian Wai Ke Za Zhi, 2013, vol. 27, no. 2, pp. 155-159. (in Chinese)

27. Frosch K.H., Balcarek P., Walde T., Stürmer K.M. A new posterolateral approach without fibula osteotomy for the treatment of tibial plateau fractures. J. Orthop. Trauma, 2010, vol. 24, no. 8, pp. 515-520. DOI: 10.1097/BOT.0b013e3181e5e17d

28. Gavaskar A.S., Gopalan H., Tummala N.C., Srinivasan P. The extended posterolateral approach for split depression lateral tibial plateau fractures extending into the posterior column: 2 years follow up results of a prospective study. Injury, 2016, vol. 47, no. 7, pp. 1497-1500. DOI: 10.1016/j. injury.2016.04.021

Received: 29.06 .2020

\section{Information about the authors:}

1. Alexander Iu. Kochish, M.D., Ph.D., Professor, Vreden National Medical Research Center of Traumatology and Orthopedics, Saint Petersburg, Russian Federation, Medical Military Academy named after S.M. Kirov, St. Petersburg, Russian Federation,

Email: auk1959@mail.ru

2. Igor G. Belen'kii, M.D., Ph.D.,

Pavlov First St. Petersburg State Medical University, Saint Petersburg, Russian Federation,

Email: belenkiy.trauma@mail.ru

3. Mikhail A. Kislitsin, M.D., Ph.D., Professor,

Semashko City Hospital No. 38, Saint Petersburg, Russian Federation

Vreden National Medical Research Center of Traumatology and Orthopedics, Saint Petersburg, Russian Federation,

Email: 89111664610@mail.ru

4. Boris A. Maiorov, M.D., Ph.D.,

Pavlov First St. Petersburg State Medical University, Saint Petersburg, Russian Federation,

Vsevolozhsk clinical inter-district hospital, Vsevolozhsk, Leningrad region, Russian Federation,

Email: MayorovBA@vkmb.ru,bmayorov@mail.ru 